\title{
Appropriateness of Screening of Angiopathic Complications Prevention in Ambulatory Patients with Diabetes
}

\author{
Sophie Excoffier ${ }^{1}$, Manuel Raphael Blum², Nicolas Rodondi², Jacques Cornuz ${ }^{3}$, \\ Lukas Zimmerli' ${ }^{4}$, Jean-Michel Gaspoz ${ }^{1}$, Idris Guessous ${ }^{1,5,6}$ \\ ${ }^{1}$ Unit of Population Epidemiology, Division of primary care medicine, Department of Community Medicine, \\ Primary Care and Emergency Medicine, Geneva University Hospital, Geneva, Switzerland \\ ${ }^{2}$ Department of General Internal Medicine, Inselspital, University of Bern, \\ Bern, Switzerland \\ ${ }^{3}$ Department for Ambulatory Care and Community Medicine, University of Lausanne, \\ Lausanne, Switzerland \\ ${ }^{4}$ Division of Internal Medicine, University Hospital of Zurich, Zurich, Switzerland \\ ${ }^{5}$ Division of Chronic Diseases, Institute of Social and Preventive Medicine, Centre Hospitalier \\ Universitaire Vaudois, University of Lausanne, Lausanne, Switzerland \\ ${ }^{6}$ Department of Epidemiology, Rollins School of Public Health, Emory University, Atlanta, USA \\ Email: Idris.Guessous@hcuge.ch
}

Received 27 April 2015; accepted 15 June 2015; published 18 June 2015

Copyright (C) 2015 by authors and Scientific Research Publishing Inc.

This work is licensed under the Creative Commons Attribution International License (CC BY).

http://creativecommons.org/licenses/by/4.0/

(c) (i) Open Access

\section{Abstract}

Background: Preventive care of diabetic foot and eye complications is essential. However, data on the prevalence of and factors associated with screening of angiopathic complications in ambulatory patients with diabetes are very limited in Switzerland. We aimed to fill this gap of knowledge. Methods: Cross-sectional data on recommended preventive care using RAND's criteria in a random sample of patients aged 50 - 80 years in 2005-2006. Participants were recruited from 4 Swiss university primary care settings (in Lausanne, Geneva, Zürich and Basel). Scores for general preventive care in patients with and without diabetes were calculated by using generalized estimating equation binomial models. Multivariate regression models were used to identify determinants of appropriateness of angiopathic complications prevention. The main outcome measure was appropriateness of screening for angiopathic complications based on the 2005 American Diabetes Association recommendations corresponding to the period of data collection. Results: Among the 1002 patients aged 50 - 80 years, $292(29.1 \%)$ had diabetes $(101 / 292$ [34.6\%] female, mean BMI 30.7 [SD 5.7]). Fifty-nine percent had appropriate preventive foot care and $55.8 \%$ had appropriate 
preventive eye care. Only $34.6 \%$ had appropriate preventive care of both foot and eye. No differences in aggregate scores for general preventive care in patients with and without diabetes were found $(67.5 \%$ vs. $69.1 \%$, $p$ value 0.39$)$. In multivariate model, obesity was negatively $(\mathrm{OR}=0.28$, $0.15-0.53)$ and hyperlipidemia positively $(O R=2.29,1.20-4.38)$ associated with appropriate eye preventive care and with appropriate combined foot and eye preventive care $(O R=0.35,0.18$ 0.70 for obesity and $O R=2.82,1.24-6.40$ for hyperlipidemia). Conclusions: Preventive care of diabetic angiopathic complications is low among ambulatory patients despite universal health care coverage. Particular attention should be paid to obese patients with diabetes.

\section{Keywords}

Diabetes, Appropriateness, Angiopathic Complications, Prevention, Primary Care

\section{Introduction}

Diabetes and its complications are among the most important and costly chronic diseases in developed countries. It is the major cause of adult blindness, kidney disease, and lower limb amputation [1]. Cost related to diabetes and its complications is very high (e.g., \$176 billion/year in 2012 in the United States, CHF 0.88 billions/year in 1998 [1 CHF $\approx 1$ US\$ as of June 2014] in Switzerland) [2]. Particular attention should be paid to the prevention of angiopathic complications such as foot ulcers and retinopathy.

Fifteen percent of patients with diabetes will suffer from foot ulcer during their lifetime [3] [4], one out of four foot ulcers will not heal, and up to $28 \%$ will result in amputation [5]. Factors such as previous foot ulcer or amputation, peripheral neuropathy, smoking, minor trauma, impaired visual acuity, and foot deformities have been associated with increased risk of foot ulcers [6]-[9].

Diabetic retinopathy is one of the most important causes of visual loss in the world. Patients with diabetes have a 25 times increased risk of blindness in comparison with the general population [10]. Because most patients remain asymptomatic until the very late stage, appropriate regular screening is essential [4] [11].

Guidelines from the American Diabetes Association (ADA) recommend annual careful exam of feet by the primary care physician, including inspection (skin integrity, foot deformities, callus), research of pedial pulses, test for neuropathy, and advice for prophylactic foot care [1]. The European Association for the Study of Diabetes (EASD) 2013 guidelines recommend annual exam of feet including inspection of indirect signs of ischemia completed with measurement of ankle brachial index [12]. Retinopathy screening by an ophthalmologist is recommended annually for patients with diabetes [1] in both guidelines.

Data from the U.S. National Health and Nutrition Examination Survey and the Behavioral Risk Factor Surveillance System have been used to evaluate the 1999-2010 trends in quality of care in patients with diabetes. While annual eye examination prevalence did not change, glycemic control increased by $7.9 \%$, and annual foot examination increased by $6.8 \%$ [13].

Data on the quality of preventive care of angiopathic complications in patients with diabetes in Switzerland are very limited. A 2007 review of medical file and assessment with 186 community-based primary physicians in the French-speaking part of Switzerland [14] showed that screening and counselling was adequate but regular follow-up of microangiopathic complications was suboptimal (62\% annual eye examination and $65 \%$ annual foot examination). The quality of prevention and management of a random sample of 1002 patients from 4 Swiss university primary care settings has been semi-quantitatively assessed in a retrospective cohort [15]. Appropriateness of the prevention of angiopathic complications (i.e., foot ulcers, retinopathy) was clearly lower than other preventive care (e.g., control of Hb1Ac, arterial blood pressure, glucose and cholesterol levels). Factors associated with the quality of care and prevention of angiopathic complications in Switzerland are currently unknown.

Recognizing this, we aimed to assess the prevalence and determinants of appropriate prevention of foot ulcer and retinopathy in patients with diabetes in Switzerland. For the purpose of the study, we defined appropriateness of care when annual foot and/or eye exam was annually completed, using international recommendations. Specifically, we assessed whether demographic (e.g., age, gender, origin), socio-economic status (e.g., marital 
status, legal status, insurance status), and comorbidities (e.g., obesity, smoking, psychiatric disorders) were associated with appropriate prevention of foot ulcer and retinopathy preventive care in patients with diabetes. We also compared the use of general recommended preventive care in patients with and without diabetes. Switzerland offers a particular study setting to assess preventive care as it is characterized by universal health insurance coverage. Health insurance coverage in Switzerland is compulsory and insurance premiums are paid independently of income. The patient pays part of the cost of treatment (an annual flat deductible according to which premiums are adjusted, and a 10\% co-pay of the costs up to an annual amount of CHF 700). In the last ten years, health insurance premiums increased by $77 \%$ [16].

\section{Methods}

\subsection{Study Design}

We used data from the Corif study [15], which has been described elsewhere [14] [17]. Briefly, informations from medical charts have been abstracted from 1002 patients randomly selected in four of the five Swiss university centers (Lausanne, Geneva, Zürich and Basel), aged 50 to 80 years, followed in 2005-2006. Diabetes was defined as at least one prescription of insulin or oral hypoglycemic agent, at least 2 outpatient diagnoses of diabetes or one outpatient diagnosis of diabetes plus HbA1c $\geq 7 \%$, at least one hospital discharge with a primary diabetes-related diagnosis, at least 2 fasting glycemia $\geq 7 \mathrm{mmol} / 1$ or at least 2 times 2-hour plasma glucose $\geq 11$ mmol/l during an oral glucose tolerance test [18]. Among 1002 patients, 292 (29.1\%) had diabetes. Data abstracted included socio-demographic factors, comorbidities, and 37 selected indicators for chronic and preventive care. The indicators were derived from RAND’s Quality QA Tools, a system established for evaluation of quality of care, based on review of the literature and confronted choice of experts [19]-[21], developed by the RAND Health group in the US.

\subsection{Statistical Analysis}

Continuous variables were expressed as medians (interquartile range, IQR) or means (standard deviation, SD). The difference in median or means between the two groups (appropriate versus inappropriate care) was tested using Wilcoxon rank test or Student's test, and two-sided p-values were reported. Categorical variables were expressed as number and percentage. $\mathrm{P}$ value was calculated by $\mathrm{Chi}^{2}$ test or exact Fisher test. We calculated the proportion of patients with appropriate foot and eye care following the 2005 ADA recommendations, the year of the Corif study recruitment [1].

Last update of ADA recommendations from 2014 [22] concerning foot and eye preventive care are very similar to 2005. According to these guidelines, preventive care was considered appropriate if done at least annually, or inappropriate otherwise. Appropriate foot exam was defined as annual pallesthesia and/or annual visual exams.

To determine and compare the prevalence of appropriateness of general preventive care (others than particular recommended measurements for screening of diabetic complications) in patients with and without diabetes, global aggregate scores were compared. Aggregate scores were calculated using generalized estimating equation binomial models by dividing the number of provided recommended care by the number of times the patients were eligible for, as described elsewhere [15]. As obesity appeared to be a major determinant of angiopathic complications, we also compared the global aggregate score of general recommended preventive care between obese and non-obese patients. We used multivariable generalized linear regression to determine factors associated with appropriateness of preventive care for angiopathic complications. We a priori selected considered socio-economic, demographic, and comorbidities factors that may influence diabetes care. To build the model, factors associated with foot and/or eye angiopathic complications preventive care in univariate analysis were entered in the final multivariable model. Age, sex, and center were forced into the model.

For the purpose of this study, obesity was defined as BMI $\geq 30 \mathrm{~kg} / \mathrm{m}^{2}$; occupation categorized as retired, employed, at home/in education/other, and social aid/unemployed; civil status as married, divorced or separated, single or widow/-er. Hyperlipidemia was defined as any lipid-lowering treatment or if any previous LDL cholesterol value was equal to or higher than the risk-appropriate cut-point value defined by NCEP ATP III. Number of outpatient visits to the general practitioner concerned the 2-year review period only. Family history of cardiovascular disease was considered positive if a man below 55 years of age or a woman below 65 years of 
age in the family had coronary heart disease (angina, myocardial infarction).

Statistical significance was considered for $\mathrm{p}<0.05$. Statistical analyses were performed with Stata version 12 (Stata Corporation, College Station, TX, USA).

\section{Results}

The main characteristics of the patients with and without diabetes included in the Corif study are presented in Table 1. Patients with $(\mathrm{N}=292,29.1 \%)$ and without diabetes $(\mathrm{N}=710,70.9 \%)$ differed by several means such as sex, birth place, legal status, occupation, cardiovascular diseases, hyperlipidemia, hypertension, and obesity. The median (IQR) number of outpatient visits during the two years of the study was 12 (9 - 17) and 10 (6 - 14) in patients with and without diabetes ( $\mathrm{p}$ value $<0.001$ ), respectively.

Among patients with diabetes, the mean (SD) age and BMI were $63.5(7.7)$ years and $30.7(5.7) \mathrm{kg} / \mathrm{m}^{2}$, respectively. Thirty-five percent were women, $31.0 \%$ current smokers, $79.5 \%$ had dyslipidemia, $87.7 \%$ hypertension, $43.5 \%$ cardiovascular disease and $26.4 \%$ chronic pulmonary disease. Among the 292 patients with diabetes, 5 (1.7\%) and 56 (19.2\%) had a history of amputation and diabetic retinopathy, respectively.

\subsection{Prevalence of Appropriate Angiopathic Complications Preventive Care}

Sixty percent of the patients with diabetes had appropriate annual foot exam, and $55.8 \%$ of the patients with diabetes had appropriate annual eye exam (Figure 1).

Nineteen percent of patients with diabetes had neither annual eye exam nor annual foot exam; $21.2 \%$ had annual eye exam but no annual foot exam; $24.7 \%$ had annual foot exam but no annual eye exam; and 34.6\% had annual foot and eye exams (Supplementary Figure S1). Among the 173 patients with diabetes and annual foot exam, 79.2\% had both foot pallesthesia and foot visual exams; $2.9 \%$ had pallesthesia only; $17.9 \%$ had foot visual exam only (Supplementary Figure S2).

Twenty-one percent of patients with diabetes were considered as having appropriate foot preventive care although the exam was incomplete (either no pallesthesia or no foot visual exam).

\subsection{General Preventive Recommended Care}

Compared to patients without diabetes, patients with diabetes had a similar aggregate score for general preventive care (67.5\% vs. 69.1\% in patients without diabetes, p value 0.39) (Supplementary Table S1).

\subsection{Determinants of Appropriateness of Foot and Eye Preventive Care}

In univariate analysis, BMI, obesity, family history of cardiovascular disease, hyperlipidemia, follow-up visit at least 2x/year and Hb1Ac controlled at least 2x/year were associated with combined appropriate care of foot and eye exam at least once a year (Supplementary Table S2). Work, civil status, number of visits to the general practitioner, family history of cardiovascular disease, blood sugar monitoring if on insulin therapy, follow-up visit at least 2x/year and control of Hb1Ac at least 2x/year were associated with appropriate foot preventive care. BMI, obesity, and hyperlipidemia were associated with appropriate eye preventive care (Supplementary Table S2). Among these factors, obesity and hyperlipidemia remained independently associated with appropriateness of combined foot and eye preventive care in multivariate analysis (Table 2). Obesity was negatively associated with appropriateness of combined foot and eye preventive care. Compared to non-obese patients with diabetes, obese patients with diabetes were less likely to have appropriateness of combined foot and eye preventive care (Odds Ratio OR: $0.35,95 \%$ CI 0.18 - 0.70). The association between obesity and appropriateness of preventive care for angiopathic complications was also found for eye (OR 0.28, 95\%CI 0.15 - 0.53 ) but not for foot exams (OR 1.26, 95\%CI 0.61 - 2.59). Associations appeared to be specific to obesity as no association was found in overweight patients with diabetes $(\mathrm{N}=86)\left(\mathrm{OR}_{\text {overweight }} 1.39,95 \% \mathrm{CI} 0.47-4.11, \mathrm{p}=0.55\right.$ for combined foot and eye preventive care and $\mathrm{OR}_{\text {overweight }} 1.19,95 \%$ CI $0.44-3.24, \mathrm{p}=0.74$ for eye preventive care only).

Sixty percent of non-obese patients had appropriate eye preventive care compared to $40.2 \%$ of obese patients with diabetes $(\mathrm{p}<0.001)$ (Figure 2). Forty-nine percent of non-obese patients with diabetes had appropriate foot preventive care compared to $51.0 \%$ of obese patients with diabetes $(\mathrm{p}=0.54)$. Combined foot and eye preventive care was appropriate in $59.5 \%$ of non-obese patients with diabetes and $40.5 \%$ of obese patients with diabetes $(\mathrm{p}=0.003)$. 
Table 1. Characteristics of the patients included in the CoRiF study (2005-2006), by diabetes status.

\begin{tabular}{|c|c|c|c|c|}
\hline Characteristics & $\begin{array}{l}\text { All patients } \\
(\mathrm{N}=1002)\end{array}$ & $\begin{array}{c}\text { Patients } \\
\text { with diabetes } \\
(\mathrm{N}=292)\end{array}$ & $\begin{array}{c}\text { Patients } \\
\text { without diabetes } \\
(\mathrm{N}=710)\end{array}$ & $\mathrm{p}$ value \\
\hline Age, mean (SD) & $63.5(8.3)$ & $63.5(7.7)$ & $63.5(8.5)$ & 0.93 \\
\hline Range, minimum-maximum & $50-80$ & $50-80$ & $50-80$ & \\
\hline Women, $N(\%)$ & $445 / 1002(44.4)$ & 101/292 (34.6) & $344 / 710(48.5)$ & $<0.001$ \\
\hline Birth place, N (\%) & & & & 0.008 \\
\hline Europe & 197/992 (19.7) & $58 / 290(20)$ & 137/702 (19.5) & \\
\hline Eastern europe & 177/992 (17.8) & 66/290 (22.8) & $111 / 702(15.8)$ & \\
\hline Africa & $59 / 992(6.0)$ & $24 / 290(8.3)$ & $35 / 702(5.0)$ & \\
\hline Latin America and other & 102/992 (10.3) & 24/290 (8.3) & 78/702 (11.1) & \\
\hline Switzerland & 459/992 (46.3) & $118 / 290(40.7)$ & $341 / 702(48.6)$ & \\
\hline Legal status, N (\%) & & & & 0.001 \\
\hline Swiss & 101/507 (19.9) & 22/166 (13.3) & 79/341 (23.2) & \\
\hline Residence permit & $325 / 507(64.1)$ & $125 / 166(75.3)$ & 200/341 (58.6) & \\
\hline Asylum seeker, demand rejected or illegal & 81/507 (16.0) & 19/166 (11.5) & 62/341 (18.2) & \\
\hline Occupation, N (\%) & & & & $<0.001$ \\
\hline Retired & 372/982 (37.9) & 107/287 (37.3) & 265/695 (38.1) & \\
\hline Employed & 285/982 (29.0) & 60/287 (20.9) & 225/695 (32.4) & \\
\hline At home or in education or other & 118/982 (12.0) & 36/287 (12.5) & 82/695 (11.8) & \\
\hline Social aid or unemployed & 207/982 (21.1) & 84/287 (29.3) & 123/695 (17.7) & \\
\hline Civil status, N (\%) & & & & 0.36 \\
\hline Married & 506/993 (51.0) & $155 / 290(53.5)$ & 351/703 (49.9) & \\
\hline Divorced, separated & 233/993 (23.5) & 72/290 (24.8) & $161 / 703(22.9)$ & \\
\hline Single & 151/993 (15.2) & 38/290 (13.1) & 113/703 (16.1) & \\
\hline Widow/-er & 103/993 (10.4) & 25/290 (8.6) & 78/703 (11.1) & \\
\hline \multicolumn{5}{|l|}{ Comorbid conditions, N (\%) } \\
\hline Cardiovascular disease & $364 / 1002(36.3)$ & $127 / 292(43.5)$ & 237/710 (33.4) & 0.002 \\
\hline Chronic pulmonary disease $^{1}$ & $261 / 1002(26.1)$ & 77/292 (26.4) & $184 / 710(25.9)$ & 0.88 \\
\hline Chronic gastrointestinal disease & 329/1002 (32.8) & 86/292 (29.5) & $243 / 710(34.2)$ & 0.14 \\
\hline Cancer & $142 / 1002(14.2)$ & 43/292(14.7) & 99/710 (13.9) & 0.75 \\
\hline Dementia & 24/1002 (2.4) & 6/292 (2.1) & $18 / 710(2.5)$ & 0.82 \\
\hline AIDS & 13/1002 (1.3) & $1 / 292(0.3)$ & $12 / 710(1.7)$ & 0.12 \\
\hline Psychiatric disorders ${ }^{1}$ & 294/1002 (29.3) & 83/292 (28.4) & $211 / 710(29.7)$ & 0.68 \\
\hline \multicolumn{5}{|l|}{ Number of GP visits over 2 years } \\
\hline Median (interquartile range) & $10(7-15)$ & $12(9-17)$ & $10(6-14)$ & $<0.001$ \\
\hline Range, minimum-maximum & $2.0-63.0$ & $3.0-48.0$ & $2.0-63.0$ & \\
\hline \multicolumn{5}{|l|}{ Cardiovascular risk factors, $\mathrm{N}(\%)$} \\
\hline Hyperlipidemia & $622 / 1001(62.1)$ & 232/292 (79.5) & $390 / 709(55.0)$ & $<0.001$ \\
\hline Hypertension & $753 / 1002(75.2)$ & 256/292 (87.7) & $497 / 710(70.0)$ & $<0.001$ \\
\hline Diabetic complications & $151 / 1002(15.1)$ & $151 / 292(51.7)$ & $0 / 710(0.0)$ & $<0.001$ \\
\hline Family history of cardiovascular disease & 99/1002 (9.9) & 24/291 (8.3) & 75/710 (10.6) & 0.27 \\
\hline Current smoker ${ }^{1}$ & 230/789 (29.2) & 71/227 (31.3) & 159/562 (28.3) & 0.40 \\
\hline Obesity (BMI $\geq 30$ ) & 288/759 (37.9) & $113 / 225(50.2)$ & $175 / 534(32.8)$ & $<0.001$ \\
\hline
\end{tabular}

${ }^{1}$ Numbers may differ from Collet et al. [15] as variables were categorized differently. 
Table 2. Multivariate associations (Odds ratio and 95\% confidence interval) of characteristics with appropriate ${ }^{*}$ preventive care for angiopathic complications in the 292 patients with diabetes in the Corif study (2005-2006).

\begin{tabular}{|c|c|c|c|c|c|c|c|c|c|}
\hline & \multicolumn{3}{|c|}{$\begin{array}{c}\text { Combined foot and eye } \\
\text { preventive care }\end{array}$} & \multicolumn{3}{|c|}{ Foot care } & \multicolumn{3}{|c|}{ Eye care } \\
\hline & Odds Ratio $^{1}$ & $95 \% \mathrm{CI}$ & p value & Odds Ratio $^{1}$ & $95 \%$ CI & P value & Odds Ratio $^{1}$ & $95 \% \mathrm{CI}$ & p value \\
\hline \multicolumn{10}{|l|}{ Occupation } \\
\hline Social aid/unemployed & Ref & & & Ref & & & Ref & & \\
\hline At home or in education & 0.16 & $0.04-0.59$ & 0.006 & 0.18 & $0.05-0.75$ & 0.018 & 0.75 & $0.21-2.69$ & 0.66 \\
\hline Employed & 0.36 & $0.13-1.01$ & 0.053 & 0.36 & $0.12-1.06$ & 0.063 & 0.53 & $0.22-1.27$ & 0.16 \\
\hline Retired & 0.69 & $0.24-1.96$ & 0.49 & 0.64 & $0.18-2.20$ & 0.48 & 1.21 & $0.43-2.91$ & 0.81 \\
\hline \multicolumn{10}{|l|}{ Civil status } \\
\hline Single & Ref & & & Ref & & & Ref & & \\
\hline Divorced, separated & 1.55 & $0.58-4.15$ & 0.38 & 5.27 & $1.64-16.90$ & 0.005 & 1.29 & $0.50-3.37$ & 0.60 \\
\hline Widow, -er & 1.09 & $0.30-3.99$ & 0.90 & 2.05 & $0.50-8.47$ & 0.32 & $1.00-0.66$ & $0.28-3.61$ & 1.00 \\
\hline Married & 1.32 & $0.51-3.43$ & 0.56 & 3.83 & $1.32-11.10$ & 0.013 & 1.15 & $0.47-2.82$ & 0.76 \\
\hline Number of visit to GP over 2 years ${ }^{2}$ & 0.98 & $0.93-1.03$ & 0.38 & 1.02 & $0.97-1.07$ & 0.53 & 1.00 & $0.96-1.05$ & 0.85 \\
\hline Obesity $\left(\mathrm{BMI} \geq 30 \mathrm{~kg} / \mathrm{m}^{2}\right)$ & 0.35 & $0.18-0.70$ & 0.003 & 1.26 & $0.61-2.59$ & 0.54 & 0.28 & $0.15-0.53$ & $<0.001$ \\
\hline $\begin{array}{c}\text { Family history of } \\
\text { cardiovascular disease }^{3}\end{array}$ & 2.22 & $0.70-7.05$ & 0.18 & 1.84 & $0.52-6.51$ & 0.34 & 2.00 & $0.68-5.88$ & 0.21 \\
\hline Hyperlipidemia $^{4}$ & 2.82 & $1.24-6.40$ & 0.013 & 2.05 & $0.87-4.82$ & 0.10 & 2.29 & $1.20-4.38$ & 0.012 \\
\hline $\begin{array}{l}\text { Blood sugar monitoring } \\
\text { at home if insulin therapy }\end{array}$ & 0.88 & $0.45-1.70$ & 0.70 & 0.62 & $0.27-1.44$ & 0.27 & 0.94 & $0.51-1.74$ & 0.84 \\
\hline Follow-up visit at least 2 x/year & 1.76 & $0.61-5.03$ & 0.29 & 4.02 & $1.35-11.92$ & 0.012 & 1.31 & $0.45-3.80$ & 0.62 \\
\hline Hb1Ac at least $2 x / y e a r$ & 2.27 & $0.99-5.21$ & 0.052 & 1.75 & $0.76-4.06$ & 0.19 & 1.58 & $0.80-3.17$ & 0.19 \\
\hline
\end{tabular}

*appropriateness of care was based on ADA recommendations and not on RAND QA Tool; ${ }^{1}$ associations are adjusted for variables listed in the table as well as for age, sex and study center; ${ }^{2}$ number of outpatient visits to the general practitioner concerned the 2 -year review period only; ${ }^{3}$ positive if a man $<55$ y or a woman $<65 \mathrm{y}$ in the family had coronary heart disease (angina, myocardial infarction); ${ }^{4}$ hyperlipidemia was considered if any lipid-lowering treatment or if any previous LDL cholesterol value $\geq$ risk-appropriate cut-point value defined by NCEP ATP III.

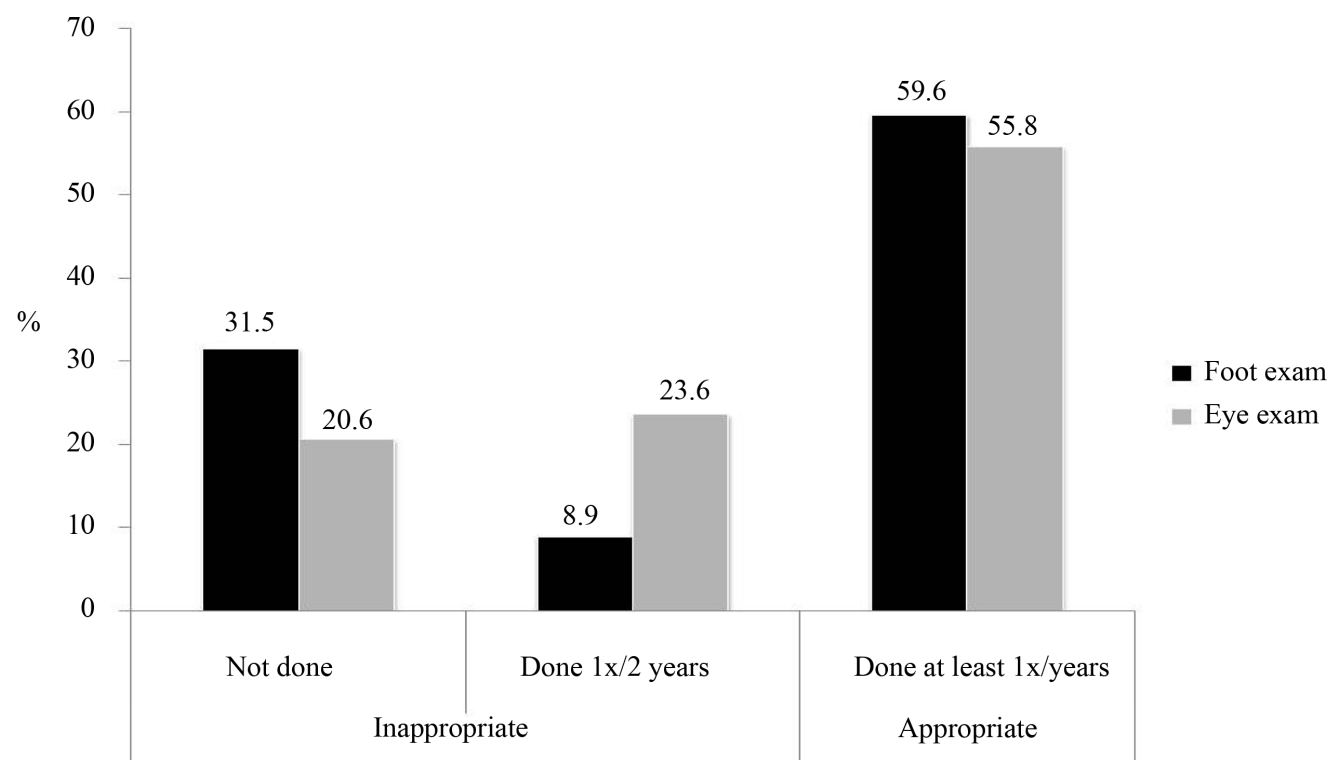

Figure 1. Prevalence of foot and eye exam in 292 patients with diabetes from the Corif study (2005-2006). 


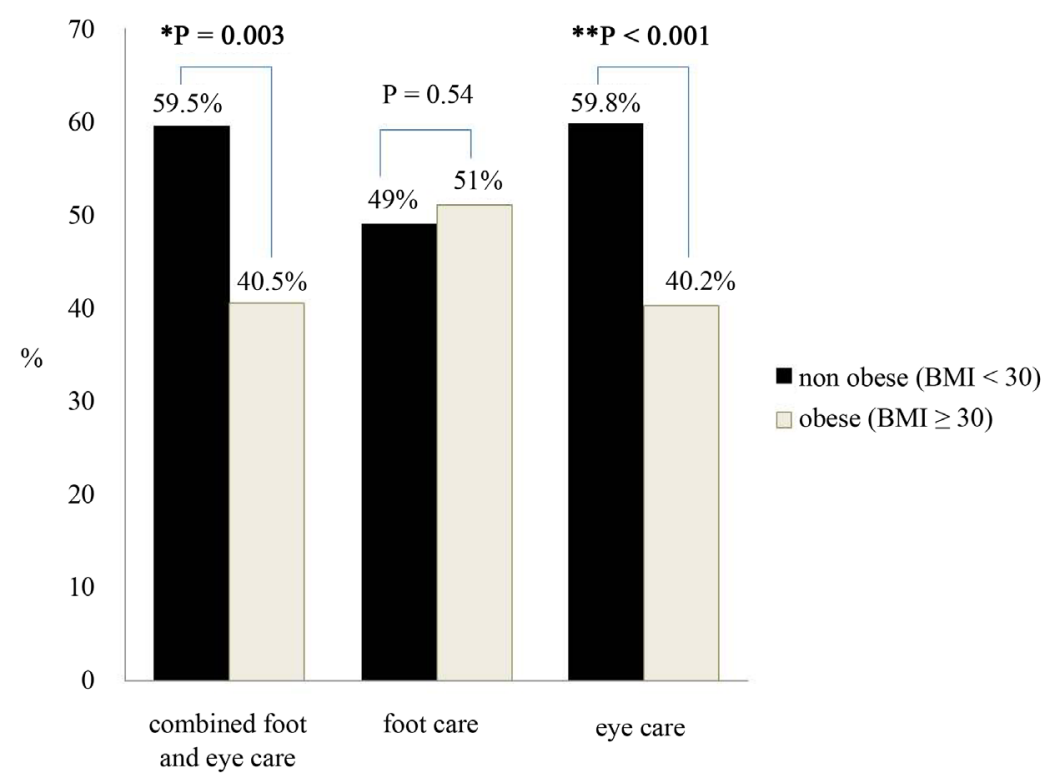

Figure 2. Proportion of appropriate care in the corif study (2005-2006), by obesity status ( $p$ values based in multivariate analysis adjusted for age, sex, study center, occupation, civil status, number of visits to GP over the two years of study, obesity, family history of cardiovascular disease, hyperlipidemia, blood sugar monitoring at home in case of insulin therapy, follow-up visit at least twice annually and measurement of Hb1Ac at least twice annually).

Of note, among the 56 patients with a history of diabetic retinopathy, $73.2 \%$ had appropriate eye preventive care and 3 among the 5 patients (60\%) with diabetes and a past amputation had appropriate foot preventive care.

Hyperlipidemia was positively associated with combined foot and eye preventive care (OR 2.82, 95\% CI 1.24 - 6.40) and eye preventive care only (OR 2.29, 95\% CI 1.20 - 4.38).

Compared with social aid or unemployed, patients at home or in education were significantly less likely to have combined foot and eye preventive care (OR 0.16, 95\% CI 0.04 - 0.59), and particularly foot preventive care (0.18, 95\% CI $0.05-0.75)$.

\section{Discussion}

Using data from a random sample of patients with and without diabetes aged 50 - 80 years followed over 2 years (2005-2006) in 4 Swiss university primary care settings, we found that inappropriate foot and eye preventive care was frequent among patients with diabetes. Obesity was independently and negatively associated with appropriateness of preventive care for diabetic retinopathy.

While we found that patients with diabetes received as much general recommended preventive care as patients without diabetes, inappropriateness of angiopathic preventive care in patients with diabetes was frequent (57 patients, 19.5\%) had neither annual eye exam, nor annual foot exam during the review period) with potential consequences on morbidity related to limb amputation and risk of impaired visual acuity or blindness. Delayed eye preventive care can result in greater risk of retinopathy [11]. Of note, one out of five patients with diabetes who had annual foot exam had actually an incomplete care with only pallesthesia or visual exams.

Obesity was negatively associated with appropriate combined foot and eye preventive care and specifically with eye preventive care. We found that compared to non-obese patients with diabetes, obese patients with diabetes were less likely to have appropriate preventive care for angiopathic complications. This association between obesity and eye preventive care was independent of major potential confounders. Further adjustment for smoking status, which is known to be often associated with screening and obesity, did not change meaningfully the results. The lower prevalence of appropriate eye preventive care among obese patients with diabetes compared to non-obese patients with diabetes is of particular importance given that obesity might be an independent risk factor for diabetic retinopathy. While the relationship of obesity with angiopathic complications care in pa- 
tients with diabetes has been sparsely explored, obesity has been positively associated with diabetic retinopathy [23]-[26]. Mechanisms such as inflammation and endothelial dysfunction have been proposed to explain the increased risk of diabetic retinopathy in obese patients [24] [25]; our findings suggest that suboptimal eye preventive care might be another explanation.

Some studies have investigated the association between obesity and appropriate preventive care, particularly in preventive cancer screening. Results are conflicting with some studies reporting less preventive care in breast, cervical, and colorectal cancer in obese than in non-obese adults [27]-[31], while other more recent studies reported no differences [31]-[34]. Methodology differences and selection of patients may explain, in part, these divergent results [33]. Patients- and healthcare providers-related barriers to preventive care in obese adults including unadapted equipment [30], reluctance to physical exam because of embarrassment [35] [36], and perceived lack of motivation/compliance [37]-[40] have been reported. The high number of comorbidities in obese patients has been suggested to explain, in part, the suboptimal preventive care generally reported in obese patients [35]. But in our study, obese patients were not less likely to have general preventive care (global aggregate score for general preventive care for obese vs non-obese patients: 73.0 vs 75.3, p = 0.08) (Table S3). In addition, patients with diabetes and obesity presented a very similar aggregate score for general preventive care (72.0\%, 95\% CI 68.9 - 75.0) than patients without diabetes or obesity (75.7, 95\% CI 74.0 - 77.3).

This should be interpreted with the fact that patients with diabetes have significantly more GP visits compared to patients without diabetes. This suggests that the medical care by GPs can also be improved.

Whether obese patients are at greater risk of diabetic retinopathy because of physiological mechanisms or suboptimal preventive care or both, our findings support the need for implementing interventions to improve eye preventive care among obese patients.

Hyperlipidemia was positively associated with appropriate eye and combined foot and eye preventive care. It is possible that patient with diabetes and hyperlipidemia requires regular lipid screening that may raise physician's attention to the prevention of others cardiovascular risk factors or angiopathic complications. Of note, some studies suggest dyslipidemia as a risk factor in combination with suboptimal glycemic control and high blood pressure for diabetic retinopathy [26].

We found no statistical interaction between hyperlipidemia and obesity ( $\mathrm{p}$ value for interaction $=0.69$ ).

Finally, occupation and civil status were associated with appropriate care for angiopathic complications. Previous studies have explored the associations between race/ethnicity and income with appropriatenes of care in patients with diabetes and results have been inconsistant. The role of occupation and civil status is worthy of future research.

\section{Strengths and Limitations}

Our study highlights a particularly vulnerable group of patients with obesity and diabetes, which requires special attention from the general practitioner. To our knowledge, this is the first study to demonstrate a strong association between obesity and inappropriateness of eye preventive care. Results from our study should be interpreted in the light of its limitations. Causal inference is not possible in cross-sectional studies. We lack information on the duration and severity of diabetes. Our study is limited to patients aged 50 - 80 years old visiting university primary care settings and our results may not be generalizable to other age groups and/or settings. Our study is based on data available from abstracted medical charts. Information abstracted from medical charts has limitations [41]-[43]. For example, measurements of quality of care was 5\% lower using clinical vignettes and $10 \%$ lower using standardized patients, compared with medical chart abstraction [43]. We cannot exclude that some care may have been appropriately done but not reported in the medical chart, especially for eye exam that might have been done by an external physician. Yet, to ensure continuity of care in a context of frequent changes of physicians in university primary care settings, systematic reporting in the medical file is essential [44], and missing information about preventive care in patients with diabetes could suggest inappropriate care per se.

The small number of patients with diabetes included in our analysis is an important limitation and our analysis may have lacked statistical power. For example, in contrast to some studies, appropriate preventive care for angiopathic complications in patients with diabetes was not independently associated with age, race, legal status or religion in our study [45] [46]. Insufficient statistical power might explain, at least in part, this lack of association. For foot exam, the ADA recommends visual exam, pallesthesia and neurological exam, and palpation of pedial pulses. We lack data on neurological exam and pedial pulse palpation. We lack information on preventive 
care performed before the study 2-year period as well as information on the severity of angiopathic complications. For eye preventive care, it is possible that some patients with one or more normal previous eye exam had less frequent exams in line with the ADA recommendations [1]. Different guidelines for preventive care in patients with diabetes exist [12] [47]. We used the 2005 ADA recommendations to define appropriate preventive care in patients with diabetes, which suggest annual foot and eye exams. Other major guidelines such as the National Institute of Health and Care Excellence clinical guidelines are in line with the ADA annual recommendation [47]. By contrast, the RANDS's Quality Tools developed in this study defined appropriate foot care as foot exam twice a year. Of note, using the RANDS's Quality Tools instead of the ADA would have led to even more frequent inappropriate care.

\section{Conclusion}

Despite health care universal coverage, preventive care of diabetic angiopathic complications (foot and eye complications) is frequently inappropriate among ambulatory patients. Preventive eye care is particularly inappropriate in obese patients with diabetes. Interventions to improve angiopathic complication preventive care are warranted.

\section{Acknowledgements}

This work was supported by an investigator-initiated unrestricted grant from Pfizer (Switzerland) for collection and analysis of data, but Pfizer had no role in the study design, the choice of statistical analyses, or the preparation of the manuscript. SE was supported by the Geneva University Hospitals, Department of Community, Primary care and Emergency Medicine. An abstract of preliminary results was accepted for presentation at the 37th Society of General Internal Medicine Annual Meeting, April 2014, San Diego, CA.

\section{References}

[1] American Diabetes Association (2005) Standards of Medical Care in Diabetes. Diabetes Care, 28, S4-S36. http://dx.doi.org/10.2337/diacare.28.suppl_1.S4

[2] American Diabetes Association (2103) Economic Costs of Diabetes in the US in 2012. Diabetes Care, 36, $1033-1046$. http://dx.doi.org/10.2337/dc12-2625

[3] Abu-Qamar, M.Z. (2006) Diabetic Foot Screening: Why Is It Neglected? International Wound Journal, 3, $203-213$. http://dx.doi.org/10.1111/j.1742-481X.2006.00232.x

[4] Melville, A., Richardson, R., McIntosh, A., et al. (2000) Complications of Diabetes: Screening for Retinopathy and Management of Foot Ulcers. Quality in Health Care, 9, 137-141. http://dx.doi.org/10.1136/qhc.9.2.137

[5] Akker, K., Schaper, N.C. and International Working Group on Diabetic Foot Editorial Board (2012) The Development of Global Consensus Guidelines on the Management and Prevention of the Diabetic Foot 2011. Diabetes/Metabolism Research and Reviews, 28, 116-118. http://dx.doi.org/10.1002/dmrr.2254

[6] Hokkam, E.N. (2009) Assessment of Risk Factors in Diabetic Foot Ulceration and Their Impact on the Outcome of the Disease. Primary Care Diabetes, 3, 219-224. http://dx.doi.org/10.1016/j.pcd.2009.08.009

[7] Frykberg, R.G., Zgonis, T., Armstrong, D.G., et al. (2006) Diabetic Foot Disorders: A Clinical Practice Guideline. American College of Foot and Ankle Surgeons. Journal of Foot and Ankle Surgery, 45, S1-S60. http://dx.doi.org/10.1016/S1067-2516(07)60001-5

[8] Barshes, N.R., Sigireddi, M., Wrobel, J.S., et al. (2013) The System of Care for the Diabetic Foot: Objectives, Outcomes and Opportunities. Diabetic Foot \& Ankle, 4, Article ID: 21847 http://dx.doi.org/10.3402/dfa.v4i0.21847

[9] Moura Neto, A., Zantut-Wittmann, D.E., Fernandes, T.D., et al. (2013) Risk Factors for Ulceration and Amputation in Diabetic Foot: Study in a Cohort of 496 Patients. Endocrine, 44, 119-124. http://dx.doi.org/10.1007/s12020-012-9829-2

[10] Tomic, M., Ljubic, S., Kastelan, S., et al. (2013) Inflammation, Haemostatic Disturbance and obesity: Possible Link to Pathogenesis of Diabetic Retinopathy in Type 2 Diabetes. Mediators of Inflammation, 2013, Article ID: 818671. http://dx.doi.org/10.1155/2013/818671

[11] Scanlon, P.H., Aldington, S.J. and Stratton, I.M. (2014) Delay in Diabetic Retinopathy Screening Increases the Rate of Detection of Referable Diabetic Retinopathy. Diabetic Medicine, 31, 439-442. http://dx.doi.org/10.1111/dme.12313

[12] Rydén, L., Standl, E., Bertnik, M., et al. (2007) Guidelines on Diabetes, Pre-Diabetes, and Cardiovascular Diseases: Executive Summary. European Heart Journal, 28, 88-136. http://dx.doi.org/10.1016/s1885-5857(07)60205-9 
[13] Ali, M.K., McKeever Bullard, K., Saadine, J.B., et al. (2013) Achievement of Goals in U.S Diabetes Care, $1999-2010$. The New England Journal of Medicine, 368, 1613-1624. http://dx.doi.org/10.1056/NEJMsa1213829

[14] Bovier, P., Sebo, P., Abetel, G., et al. (2007) Adherence to Recommended Standards of Diabetes Care by Swiss Primary Care Physicians. Swiss Medical Weekly, 137, 173-181.

[15] Collet, T.H., Salamin, S., Zimmerli, L., et al. (2011) The Quality Of Primary Care in a Country with Universal Health Care Coverage. Journal of General Internal Medicine, 26, 724-730. http://dx.doi.org/10.1007/s11606-011-1674-0

[16] Guessous, I., Gaspoz, J.M., Theler, J.M. and Wolff, H. (2012) High Prevalence of Forgoing Healthcare for Economic Reasons in Switzerland: A Population-Based Study in a Region with Universal Health Insurance Coverage. Preventive Medicine, 55, 521-527. http://dx.doi.org/10.1016/j.ypmed.2012.08.005

[17] Martin, Y., Collet, T.H., Bodenmann, P., et al. (2014) The Lower Quality of Preventive Care among Forced Migrants in a Country with Universal Healthcare Coverage. Preventive Medicine, 59, 19-24. http://dx.doi.org/10.1016/j.ypmed.2013.11.006

[18] Rodondi, N., Peng, T., Karter, A.J., et al. (2006) Therapy Modifications in Response to Poorly Controlled Hypertension, Dyslipidemia, and Diabetes Mellitus. Annals of Internal Medicine, 144, 475-484. http://dx.doi.org/10.7326/0003-4819-144-7-200604040-00006

[19] McGlynn, E.A., Asch, S.M., Adams, J., et al. (2003) The Quality of Health Care Delivered to Adults in the United States. The New England Journal of Medicine, 348, 2635-2645. http://dx.doi.org/10.1056/NEJMsa022615

[20] Asch, S.M., Kerr, E.A., Keesey, J., et al. (2006) Who Is at Greatest Risk for Receiving Poor-Quality Health Care? The New England Journal of Medicine, 354, 1147-1156. http://dx.doi.org/10.1056/NEJMsa044464

[21] Asch, S., Clark Hamilton, E.G. and McGlynn, E.A. (2000) Quality of Care for General Medical Conditions: A Review of the Literature and Quality Indicators. RAND Health, Santa Monica. http://www.rand.org/pubs/monograph_reports/MR1280.html

[22] American Diabetes Association (2014) Standards of Medical Care in Diabetes. Diabetes Care, 37, S14-S80. http://dx.doi.org/10.2337/dc14-S014

[23] Dirani, M., Xie, J., Fenwick, E., et al. (2011) Are Obesity and Anthropometry Risk Factors for Diabetic Retinopathy? The Diabetes Management Project. Investigative Ophthalmology \& Visual Science, 52, 4416-4421. http://dx.doi.org/10.1167/iovs.11-7208

[24] Cheung, N. and Wong, T.Y. (2007) Obesity and Eye Disease. Survey of Ophthalmology, 52, 180-195.

[25] Kastelan, S., Tomic, M., Gverovic, Antunica, A., et al. (2013) Body Mass Index: A Risk Factor for Retinopathy in Type 2 Diabetic Patients. Mediators of Inflammation, 2013, Article ID: 436329. http://dx.doi.org/10.1155/2013/436329

[26] Van Leiden, H.A., Dekker, J.M., Moll, A.C., et al. (2002) Blood Pressure, Lipids, and Obesity Are Associated with Retinopathy: The Hoorn Study. Diabetes Care, 25, 1320-1325. http://dx.doi.org/10.2337/diacare.25.8.1320

[27] Hernandez-Boussard, T., Ahmed, S.M. and Morton, J.M. (2012) Obesity Disparities in Preventive Care: Findings from the National Ambulatory Medical Care Survey, 2005-2007. Obesity, 20, 639-644. http://dx.doi.org/10.1038/oby.2011.258

[28] Fontaine, K.R., Faith, M.S., Allison, D.B. and Cheskin, L.J. (1998) Body Weight and Health Care among Women in the General Population. Archives of Family Medicine, 7, 381-384. http://dx.doi.org/10.1001/archfami.7.4.381

[29] Wee, C.C., McCarthy, E.P., Davis, R.B. and Phillips, R.S. (2000) Screening for Cervical and Breast Cancer: Is Obesity an Unrecognised Barrier to Preventive Care? Annals of Internal Medicine, 132, 697-704. http://dx.doi.org/10.7326/0003-4819-132-9-200005020-00003

[30] Littman, A.J., Koepsell, T.D., Forsberg, C.W., et al. (2011) Preventive Care in Relation to Obesity: An Analysis of a large, National Survey. Preventive Care in Relation to Obesity, 41, 465-472. http://dx.doi.org/10.1016/j.amepre.2011.07.020

[31] Ferrante, J.M., Ohman-Strickland, P., Hudson, S.V., et al. (2006) Colorectal Cancer Screening among Obese versus Non-Obese Patients in Primary Care Practices. Cancer Detection and Prevention, 30, 459-465. http://dx.doi.org/10.1016/j.cdp.2006.09.003

[32] Kraschnewski, J.L., McCall-Hosenfeld, J.S. and Weisman, C.S. (2012) Prospective Association between Body Mass Index and Receipt of Preventive Services: Results from the Central Pennsylvania Women's Health Study (CePAWHS). Preventive Medicine, 54, 302-305. http://dx.doi.org/10.1016/j.ypmed.2012.02.010

[33] Chang, V.W., Asch, D.A. and Werner, R.M. (2010) Quality of Care among Obese Patients. The Journal of the American Medical Association, 303, 1274-1281. http://dx.doi.org/10.1001/jama.2010.339

[34] Cohen, S.S., Palmieri, R.T., Nyante, S.J., et al. (2008) Obesity and Screening for Breast, Cervical, and Colorectal Cancer in Women. Cancer, 112, 1892-1904. http://dx.doi.org/10.1002/cncr.23408 
[35] Quinn, V.P., Jacobsen, S.J., Slezak, J.M., et al. (2012) Preventive Care and Health Behaviours among Overweight/Obese Men in HMOs. American Journal of Managed Care, 18, 25-32.

[36] Ma, J., Xiao, L. and Stafford, R.S. (2009) Adult Obesity and Office-Based Quality of Care in the United States. Obesity, 17, 1077-1085. http://dx.doi.org/10.1038/oby.2008.653

[37] Ruelaz, A.R., Diefenbach, P., Simon, B., et al. (2007) Perceived Barriers to Weight Management in Primary CarePerspective of Patients and Providers. Journal of General Internal Medicine, 22, 518-522. http://dx.doi.org/10.1007/s11606-007-0125-4

[38] Rieder, A., Haller, D., Sebo, P., et al. (2010) Diabetes and Research in Primary Care: How to Improve the Care of Our Patients? Revue Médicale Suisse, 6, 1006-1009.

[39] Foster, G.D., Wadden, T.A., Makris, A.P., et al. (2003) Primary Care Physicians' Attitudes about Obesity and Its Treatment. Obesity Research, 11, 1168-1177. http://dx.doi.org/10.1038/oby.2003.161

[40] Ferrante, J.M., Piasecki, A.K., Ohman-Strickland, P., et al. (2009) Family Physicians’ Practices and Attitudes Regarding Care of Extremely Obese Patients. Obesity, 17, 1710-1716. http://dx.doi.org/10.1038/oby.2009.62

[41] Guessous, I., Juillerat, P., Pittet, V., et al. (2007) Evaluating Appropriateness of Treatment for Crohn’s Disease: Feasibility of an Explicit Approach. Digestion, 75, 46-52. http://dx.doi.org/10.1159/000101566

[42] Luck, J., Peabody, J.W., Dresselhaus, T.R., et al. (2000) How Well Does Chart Abstraction Measure Quality? A Prospective Comparison of Standardized Patients with Medical Record. The American Journal of Medicine, 108, 642-649. http://dx.doi.org/10.1016/S0002-9343(00)00363-6

[43] Peabody, J.W., Luck, J., Glassman, P., et al. (2000) Comparison of Vignettes, Standardized Patients, and Chart Abstraction: A Prospective Validation Study of 3 Methods for Measuring Quality. The Journal of the American Medical Association, 283, 1715-1722. http://dx.doi.org/10.1001/jama.283.13.1715

[44] Campbell, S.M., Roland, M.O., Shekelle, P.G., et al. (1999) Development of Review Criteria for Assessing the Quality of Management of Stable Angina, Adult Asthma, and Non-Insulin Dependent Diabetes Mellitus in General Practice. Quality in Health Care, 8, 6-15. http://dx.doi.org/10.1136/qshc.8.1.6

[45] Richard, P., Kébreau Alexandre, P., Lara, A. and Akamigbo, A. (2011) Racial and Ethnic Disparities in the Quality of Diabetes Care in a Nationally Representative Sample. Preventing Chronic Disease, 8, A142.

[46] Parikh, P.B., Yang, S., Leigh, J., et al. (2014) The Impact of Financial Barriers on Access to Care, Quality of Care and Vascular Morbidity among Patients with Diabetes and Coronary Heart Disease. Journal of General Internal Medicine, 29, 76-81. http://dx.doi.org/10.1007/s11606-013-2635-6

[47] NICE Clinical Guidelines of the National Institute for Health and Care Excellence, UK (2004).

https://www.nice.org.uk/guidance 


\section{Supplementary Tables}

Table S1. Recommended preventive care and aggregate score in the Corif study (2005-2006), by diabetes status.

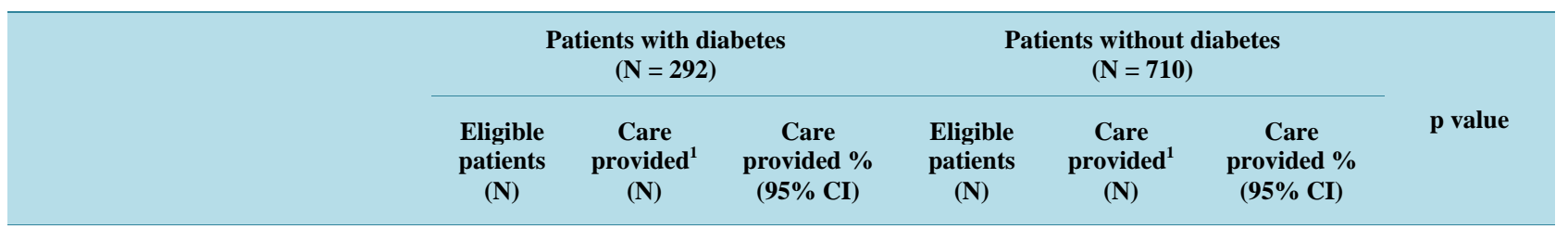

Physical examination

Annual blood pressure measurement

Weight measurement

Height measurement

Alcohol consumption counseling

Asked about drinking problem

Smoking cessation counseling

Smoking status documented

Annual advice to quit smoking

Counseling offered to

smokers attempting to quit

Pharmacotherapy offered to smokers attempting to quit if $>10$ cigarettes/day

Abstinence documented 4 weeks after smoking cessation counseling

\section{Cancer screening ${ }^{2}$}

Screening for colon cancer (aged 50 - 80)

Screening for breast cancer (aged 5 0- 70)

Influenza immunization $^{3}$

Annual influenza vaccine for patients $\geq 65$ years

Annual influenza vaccine for immunocompromissed patients $<65$ years

Global aggregate score for preventive care
280

96.0

(92.9 - 97.9)

710

672

96.2

281

(93.4 - 98.1)

710

75.3

220

$(70.0-80.2)$

710

533

671

(92.7-96.

0.86

94.5

(92.6 - 96.1)

0.44

75.1

(71.7 - 78.2)

0.99

(70.0 - 80.2)

195

$$
\begin{gathered}
66.8 \\
(61,1-72.2)
\end{gathered}
$$

710

476

67.0
$(63.4-70.5)$

0.99

76.1

41.7

5

(15.2 - 72.3)

40

19

48.0
$(31.5-63.9)$

0.71

30.9

88

43.6

$\begin{array}{ll}78 & 34\end{array}$

(32.4 - 55.3)

232

91

(32.9 - 45.8)

36.8

(33.2 - 40.4)

0.82

39.2

0.88

48

$$
\text { (29.6 - 47.2) }
$$

300

102

34.0

(28.7 - 39.7)

0.78

151

$$
34
$$

22.5

125

47

37.6

(29.1 - 46.7)

0.006

67.5

(65.5 - 69.4)
69.1

(67.8 - 70.3)
0.39

${ }^{1}$ when care was refused by eligible patients, it was considered as provided care and when care was provided less frequently than recommended, it was considered as unprovided; ${ }^{2}$ if patients had a prior diagnostic of colon or breast cancer, they were excluded from screening; ${ }^{3}$ recommendations for influenza vaccination for < 65 years: living in a nursing home, chronic cardiovascular disease, chronic obstructive pulmonary disease, renal failure, diabetes, immunosuppression, hemoglobinopathy. 
Table S2. Appropriateness of angiopathic complication preventive care, by characteristics.

\begin{tabular}{|c|c|c|c|c|c|c|c|c|c|c|}
\hline & \multicolumn{4}{|c|}{ Combined foot and eye preventive care } & \multicolumn{3}{|c|}{ Foot care } & \multicolumn{3}{|c|}{ Eye care } \\
\hline & $\mathbf{N}^{1}$ & Appropriate & Inappropriate & p value & Appropriate & Inappropriate & P value & Appropriate & Inappropriate & p value \\
\hline All patients with diabetes & 292 & 102/292 (34.9) & 190/292 (65.1) & & $173 / 292(59.3)$ & $119 / 292(40.8)$ & & $163 / 292(55.8)$ & $129 / 292(44.2)$ & \\
\hline \multicolumn{11}{|l|}{$\begin{array}{l}\text { General socio-demographic } \\
\text { characteristics }\end{array}$} \\
\hline Age, mean (SD) & 292 & $63.9(7.4)$ & $63.3(7.9)$ & 0.56 & $64.1 /(7.5)$ & $62.8(8.0)$ & 0.17 & $63.3(7.6)$ & $63.8(7.9)$ & 0.57 \\
\hline Female, N(\%) & 292 & 37/102 (36.6) & 64/190 (33.5) & 0.59 & 61/173 (35.3) & 40/119 (33.6) & 0.77 & $59 / 163(36.2)$ & $42 / 129(32.6)$ & 0.52 \\
\hline Insurance N(\%) & 210 & & & 0.67 & & & 0.80 & & & 0.56 \\
\hline Private or semi-private & & 2/86 (2.3) & 4/124 (3.2) & & 4/146 (2.7) & 2/64 (3.1) & & $2 / 116(1.7)$ & $4 / 94(4.3)$ & \\
\hline General & & 80/86 (93) & 117/124 (94.4) & & 136/146 (93.2) & 61/64 (95.3) & & $110 / 116(94.8)$ & 87/94 (92.6) & \\
\hline None & & $4 / 86(4.7)$ & 3/124 (2.4) & & 6/146 (4.1) & $1 / 64(1.6)$ & & 4/116 (3.4) & 3/94 (3.2) & \\
\hline Birth place N(\%) & 290 & & & 0.22 & & & 0.08 & & & 0.57 \\
\hline Europe & & 18/99 (18.2) & 40/191 (20.9) & & 37/171 (21.6) & 21/119 (17.7) & & 27/161 (16.8) & $31 / 129(24.0)$ & \\
\hline Eastern europe & & 17/99 (17.2) & 49/191 (25.3) & & $30 / 171(17.5)$ & 36/119 (30.3) & & 37/161 (23) & 29/129 (22.5) & \\
\hline Latin america and other & & 12/99 (12.1) & $12 / 191(6.3)$ & & 18/171 (10.5) & 6/119 (5.0) & & 15/161 (9.3) & $9 / 129(7.0)$ & \\
\hline Switzerland & & 42/99 (42.4) & 76/191 (39.8) & & $71 / 171(41.5)$ & 47/118 (39.5) & & 67/161 (41.6) & $51 / 129(39.5)$ & \\
\hline Legal status N(\%) & 166 & & & 0.36 & & & 0.58 & & & 0.32 \\
\hline Swiss & & 7/55 (12.7) & 15/111 (13.5) & & 15/98 (15.3) & 7/68 (10.3) & & 10/91 (11.0) & $12 / 75(16.0)$ & \\
\hline Residence & & 39/55 (70.9) & $86 / 111(77.5)$ & & $71 / 98$ (72.5) & $54 / 68(79.4)$ & & 68/91 (74.7) & $57 / 75(76.0)$ & \\
\hline $\begin{array}{l}\text { asylum seeker, demand } \\
\text { rejected or illegal }\end{array}$ & & 9/55 (16.4) & $10 / 111(9.0)$ & & $12 / 98(12.2)$ & 7/68 (10.3) & & 13/91 (14.3) & $6 / 75(8.0)$ & \\
\hline Religion N(\%) & 201 & & & 0.31 & & & 0.18 & & & 0.23 \\
\hline Christian & & $30 / 55(54.6)$ & $61 / 146(41.8)$ & & $53 / 100(53.0)$ & 38/101 (37.6) & & 47/109 (43.1) & 44/92 (47.8) & \\
\hline Muslim & & 13/55 (23.6) & $35 / 146(24)$ & & 20/100 (20.0) & 28/101 (27.7) & & 32/109 (29.4) & 16/92 (17.4) & \\
\hline Other & & 7/55 (12.7) & 26/146 (17.8) & & $14 / 100(14.0)$ & 19/101 (18.8) & & 17/109 (15.6) & 16/92 (17.4) & \\
\hline None & & $5 / 55(9.1)$ & 24/146 (16.4) & & 13/100 (13.0) & 16/101 (15.8) & & 13/109 (11.9) & 16/92 (17.4) & \\
\hline Occupation N(\%) & 287 & & & 0.07 & & & 0.008 & & & 0.76 \\
\hline At home, in education or other & & $7 / 100(7.0)$ & 29/187 (15.5) & & $14 / 171(8.2)$ & 22/116 (19.0) & & 22/160 (13.8) & 14/127 (11) & \\
\hline Employed & & $17 / 100(17.0)$ & 43/187 (23.0) & & 31/171 (18.1) & 29/116 (25.0) & & 31/160 (19.4) & 29/127 (22.8) & \\
\hline Retired & & $42 / 100(42.0)$ & 65/187 (34.8) & & 73/171 (42.7) & $34 / 116(29.3)$ & & $58 / 160(36.3)$ & 49/127 (38.6) & \\
\hline Civil status N(\%) & 290 & & & 0.10 & & & 0.005 & & & 0.9 \\
\hline Single & & $15 / 100(15.0)$ & 23/190 (12.1) & & 19/172 (11.1) & 19/118 (16.1) & & 23/161 (14.2) & 15/128 (11.7) & \\
\hline Divorced & & $32 / 100(32.0)$ & 40/190 (21.1) & & $55 / 172(32.0)$ & 17/118 (14.4) & & $41 / 162(25.3)$ & $31 / 128(24.2)$ & \\
\hline Widow, -er & & 9/100 (9.0) & $16 / 190(8.4)$ & & 16/172 (9.3) & $9 / 118(7.6)$ & & $13 / 162(8.0)$ & $12 / 128(9.4)$ & \\
\hline Married & & $44 / 100(44.0)$ & $111 / 190(58.4)$ & & $82 / 172(47.7)$ & 73/118 (61.9) & & $85 / 162(52.5)$ & 70/128 (54.7) & \\
\hline \multicolumn{11}{|l|}{$\begin{array}{l}\text { Health care provider's } \\
\text { characteristics }\end{array}$} \\
\hline Main physician function N(\%) & 291 & & & 0.26 & & & 0.07 & & & 0.74 \\
\hline Medical student or resident & & $90 / 100(90.0)$ & 179/191 (93.7) & & 155/172 (90.1) & 114/119 (95.8) & & 149/162 (92) & 120/129 (93) & \\
\hline Senior resident or attending & & $10 / 100(10.0)$ & $12 / 191(6.3)$ & & 17/172 (9.9) & $5 / 119(4.2)$ & & $13 / 162(8)$ & $9 / 129(7)$ & \\
\hline $\begin{array}{c}\text { Nb of visit to GP over } 2 \text { years } \\
\text { Median (IQR) }\end{array}$ & 292 & $\begin{array}{c}12.0 \\
(9.0-16.0)\end{array}$ & $12.0(8.0-17.0)$ & 0.58 & $\begin{array}{c}13.0 \\
(9.0-18.0)\end{array}$ & $\begin{array}{c}11.0 \\
(8.0-16.0)\end{array}$ & 0.031 & $12(9.0-16.0)$ & $11(8.0-18.0)$ & 0.3 \\
\hline \multicolumn{11}{|l|}{ Patients' comorbidities } \\
\hline BMI, mean (SD) & 225 & $29.7(4.5)$ & $31.4(6.3)$ & 0.035 & $30.6(5.3)$ & $31.0(6.5)$ & 0.60 & $29.8(4.7)$ & $31.9(6.6)$ & 0.005 \\
\hline $\begin{array}{c}\text { Obesity } \\
\left(\mathrm{BMI} \geq 30 \mathrm{~kg} / \mathrm{m}^{2}\right) \mathrm{N}(\%)\end{array}$ & 225 & $34 / 84(40.5)$ & 79/141 (56.0) & 0.024 & 75/147 (51.0) & $38 / 78$ (48.7) & 0.74 & 49/122 (40.2) & 64/103 (62.1) & 0.001 \\
\hline $\begin{array}{c}\text { Family history of } \\
\text { cardiovascular disease } \mathrm{N}(\%)\end{array}$ & 291 & $13 / 100(13.0)$ & 11/191 (5.8) & 0.033 & 20/172 (11.6) & 4/119 (3.4) & 0.012 & 16/162 (9.8) & 8/129 (6.2) & 0.26 \\
\hline Cardiovascular disease $^{2} \mathrm{~N}(\%)$ & 292 & 50/101 (49.5) & 77/191 (40.3) & 0.13 & 82/173 (47.4) & 45/119 (37.8) & 0.11 & 73/163 (44.8) & $54 / 127(41.9)$ & 0.62 \\
\hline Current smoker ${ }^{3} \mathrm{~N}(\%)$ & 71 & 23/71 (32.4) & $48 / 71(67.6)$ & 0.18 & $42 / 71(59.2)$ & 29/71 (40.9) & 0.23 & $39 / 71(54.9)$ & $32 / 71(45.1)$ & 0.57 \\
\hline Hyperlipidemia N(\%) & 292 & 87/101 (86.1) & 145/191 (75.9) & 0.040 & 139/173 (80.4) & 93/119 (78.2) & 0.65 & 140/163 (85.9) & 92/129 (71.3) & 0.002 \\
\hline Hypertension N(\%) & 292 & 92/101 (91.1) & 164/191 (85.9) & 0.20 & 154/173 (89.0) & $102 / 119(85.7)$ & 0.40 & 146/163 (89.6) & $110 / 129(85.3)$ & 0.27 \\
\hline
\end{tabular}




\section{Continued}

\begin{tabular}{|c|c|c|c|c|c|c|c|c|c|c|}
\hline Alcohol consumption ${ }^{4} \mathrm{~N}(\%)$ & 182 & & & 0.50 & & & 0.16 & & & 0.56 \\
\hline None & & $47 / 73(64.4)$ & 69/109 (63.3) & & 83/122 (68.0) & $33 / 60(55.0)$ & & 66/103 (64.1) & $50 / 79(63.3)$ & \\
\hline Normal & & 7/73 (9.6) & 6/109 (5.5) & & $9 / 122(7.4)$ & $4 / 60(6.7)$ & & 9/103 (8.7) & 4/79 (5.1) & \\
\hline Excessive & & $19 / 73(26.0)$ & $34 / 109$ (31.2) & & $30 / 122(24.6)$ & 23/60 (38.3) & & 28/103 (27.2) & 25/79 (31.7) & \\
\hline \multicolumn{11}{|l|}{ Other preventive care } \\
\hline Regular aspirin therapy N(\%) & 292 & 68/101 (67.3) & $115 / 191(60.2)$ & 0.23 & 109/173 (63.0) & $74 / 119(62.2)$ & 0.89 & 108/163 (66.3) & 75/129 (58.1) & 0.15 \\
\hline $\begin{array}{c}\text { Lipid measurements at least } \\
1 \mathrm{x} / 2 \text { years } N(\%)\end{array}$ & 292 & 97/101 (96.0) & 178/191 (93.2) & 0.32 & $163 / 173(94.2)$ & $112 / 119(94.1)$ & 0.97 & 156/163 (95.7) & 119/129 (92.2) & 0.21 \\
\hline $\begin{array}{l}\text { Blood sugar monitoring at } \\
\text { home if insulin therapy N(\%) }\end{array}$ & 292 & & & 0.08 & & & $<0.001$ & & & 0.38 \\
\hline yes & & 43/101 (42.6) & 58/191 (30.4) & & 75/173 (43.4) & 26/119 (21.9) & & 62/163 (38) & 39/129 (30.2) & \\
\hline no & & $0 / 101$ & 2/191 (1.1) & & $0 / 173$ & 2/119 (1.7) & & $1 / 163(0.6)$ & $1 / 129(0.8)$ & \\
\hline non applicable $e^{5}$ & & $58 / 101(57.4)$ & 131/191 (68.6) & & 98/173 (56.7) & $91 / 119(76.5)$ & & 100/163 (61.3) & 89/129 (69) & \\
\hline $\begin{array}{c}\text { Follow-up visit at least } \\
\text { 2x/year N(\%) }\end{array}$ & 292 & 95/101 (94.1) & 164/191 (85.8) & 0.035 & 164/173 (94.8) & 95/119 (79.7) & $<0.001$ & 148/163 (90.8) & 111/129 (86) & 0.2 \\
\hline Hb1Ac at least 2x/year N(\%) & 292 & 83/101 (82.2) & 127/191 (66.5) & 0.005 & 137/173 (79.2) & 73/119 (61.3) & 0.001 & $124 / 163(76.1)$ & $86 / 129(66.7)$ & 0.08 \\
\hline $\begin{array}{l}\text { Urine microalbumin/creatinine } \\
\text { ratio at least } 1 \mathrm{x} / 2 \text { years } \mathrm{N}(\%)\end{array}$ & 291 & 64/101 (63.4) & $137 / 190(72.1)$ & 0.13 & $118 / 173(68.2)$ & 83/118 (70.3) & 0.70 & $111 / 162(68.5)$ & 90/129 (69.8) & 0.66 \\
\hline
\end{tabular}

\section{Table S3. Recommended preventive care and aggregate score in the Corif study (2005-2006), by obesity status.}

\begin{tabular}{|c|c|c|c|c|c|c|c|}
\hline & \multicolumn{3}{|c|}{$\begin{array}{l}\text { Obese patients } \\
\quad(\mathbf{N}=\mathbf{2 8 8})\end{array}$} & \multicolumn{3}{|c|}{$\begin{array}{l}\text { Non-obese patients } \\
\quad(N=471)\end{array}$} & \multirow[b]{2}{*}{ p value } \\
\hline & $\begin{array}{c}\text { Eligible } \\
\text { patients }(\mathbf{N})\end{array}$ & $\begin{array}{c}\text { Care } \\
\text { provided }^{1}(\mathrm{~N})\end{array}$ & $\begin{array}{c}\text { Care } \\
\text { provided \% } \\
(95 \% \mathrm{CI})\end{array}$ & $\begin{array}{l}\text { Eligible } \\
\text { patients } \\
(\mathrm{N})\end{array}$ & $\begin{array}{c}\text { Care } \\
\text { provided }^{1} \\
(\mathrm{~N})\end{array}$ & $\begin{array}{c}\text { Care } \\
\text { provided \% } \\
(95 \% \text { CI) }\end{array}$ & \\
\hline \multicolumn{8}{|l|}{ Physical examination } \\
\hline Annual blood pressure measurement & 288 & 281 & $97.6(95.1-99.0)$ & 471 & 442 & $97.6(95.1-99.0)$ & 0.99 \\
\hline Height measurement & 288 & 284 & $98.6(96.5$ - 99.6) & 471 & 465 & 98.7 (97.2 - 99.5) & 0.99 \\
\hline \multicolumn{8}{|l|}{ Alcohol consumption counseling } \\
\hline Asked about drinking problem & 288 & 205 & $71.2(65.6$ - 76.3) & 471 & 368 & $78.1(74.1$ - 81.8) & 0.03 \\
\hline \multicolumn{8}{|l|}{ Smoking cessation counseling } \\
\hline Smoking status documented & 288 & 239 & $83.0(78.1$ - 87.1) & 471 & 407 & $86.4(83.0$ - 89.4) & 0.27 \\
\hline Annual advice to quit smoking & 65 & 50 & $76.9(64.8-86.5)$ & 113 & 79 & $70.0(60.6-78.2)$ & 0.30 \\
\hline $\begin{array}{l}\text { Pharmacotherapy offered to smokers } \\
\text { attempting to quit if }>10 \text { cigarettes/day }\end{array}$ & 23 & 9 & $39.1(19.7$ - 61.5) & 39 & 23 & $59.0(42.1-74.4)$ & 0.11 \\
\hline $\begin{array}{l}\text { Abstinence documented } 4 \text { weeks } \\
\text { after smoking cessation counseling }\end{array}$ & 13 & 8 & $61.5(31.6-86.1)$ & 31 & 14 & $45.2(27.3-64.0)$ & 0.30 \\
\hline \multicolumn{8}{|l|}{ Cancer screening ${ }^{2}$} \\
\hline Screening for colon cancer (aged 50 - 80) & 282 & 89 & $31.6(26.2$ - 37.3) & 462 & 174 & $37.7(33.2-42.3)$ & 0.10 \\
\hline Screening for breast cancer (aged 50 - 70) & 125 & 45 & $36.0(27.6-45.1)$ & 128 & 54 & $42.2(33.5-51.2)$ & 0.33 \\
\hline \multicolumn{8}{|l|}{ Influenza immunization $^{3}$} \\
\hline Annual influenza vaccine for patients $\geq 65$ years & 96 & 37 & $38.5(28.8-49.0)$ & 209 & 70 & $33.5(27.1-40.3)$ & 0.31 \\
\hline $\begin{array}{l}\text { Annual influenza vaccine for } \\
\text { immunocompromised patients }<65 \text { years }\end{array}$ & 99 & 27 & $27.3(18.8-37.1)$ & 108 & 29 & $26.9(18.8-36.2)$ & 0.99 \\
\hline Global aggregate score for preventive care & & & 73.0 (71.1 - 74.8) & & & 75.3 (73.8 - 76.7) & 0.08 \\
\hline
\end{tabular}

${ }^{1}$ when care was refused by eligible patients, it was considered as provided care and when care was provided less frequently than recommended, it was considered as unprovided. ${ }^{2}$ if patients had a prior diagnostic of colon or breast cancer, they were excluded from screening. ${ }^{3}$ recommendations for influenza vaccination for < 65 years: living in a nursing home, chronic cardiovascular disease, chronic obstructive pulmonary disease, renal failure, diabetes, immunosuppression, hemoglobinopathy. 


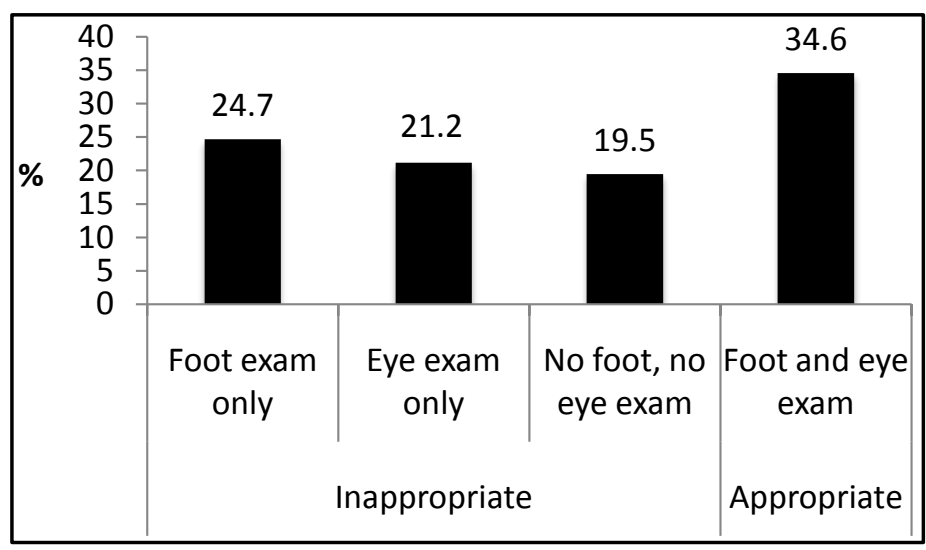

Figure S1. Prevention of angiopathic complications in 292 patients with diabetes included in the Corif Study (2005-2006).

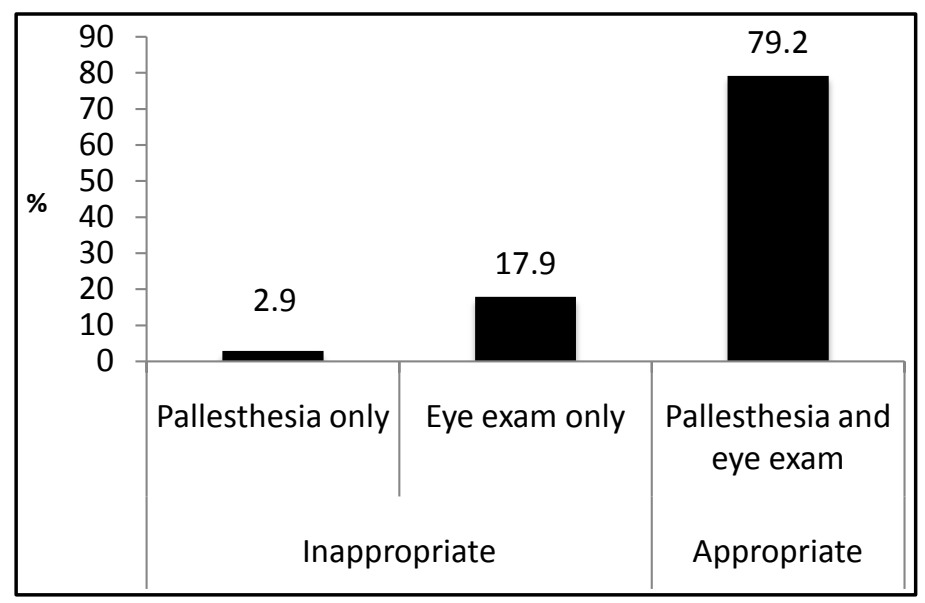

Figure S2. Details of foot exam in 173 patients with diabetes with appropriate annual foot exam included in the Corif Study (2005-2006). 